\title{
COMMUTER BEHAVIORAL MODEL FOR THE PILOT PROGRAM OF ELECTRONIC TOLL SYSTEM ON KOREAN EXPRESS HIGHWAYS
}

\author{
Kyungwoo Kang \\ Hanyang University, Korea
}

\begin{abstract}
In recent years, congestion pricing has gained popularity as a method for managing peak-period congestion on major roads in urban areas. Intelligent Transportation Systems (ITS) technology has resulted in an electronic toll collection (ETC) system called "Hi-Pass," which is operated by the Korea Highway Cooperation for the pilot program. The limited sections of highway involved in the program have gained good approval ratings from motorists.

In this research, the Korean highway toll system was analyzed with respect to the brief legal history of the toll road, collection method and levels. In addition, the electronic toll collection policy for foreign countries including France, Norway, and Italy are investigated. The toll system of each country is clearly differentiated with regard to the institution, regulation and the country's economy.

In the review of the pilot ETC program "Hi-pass" system in Korea, several important factors were found. First, a more concrete marketing strategy for ETC users will needed to encourage continued usage. In particular, frequent users and higher-income users adopted the ETC system more easily than others did. Second, in order to encourage the non-user to try the ETC system, the costs of on-board units must be kept reasonably low (about \$50), and aggressive discounts (about 3-5\% compared to the current 1\%) are needed.
\end{abstract}

